\title{
OPERAÇÃO ODESSA: A FUGA DOS CRIMINOSOS DE GUERRA NAZISTAS PARA A AMÉRICA LATINA APÓS A SEGUNDA GUERRA MUNDIAL E OS CAÇADORES DE NAZISTAS
}

\author{
Marcos Eduardo Meinerz
}

\begin{abstract}
RESUMO
0 presente artigo visa analisar o porquê da América Latina, principalmente a Argentina, ter sido a região do mundo que mais abrigou nazistas criminosos de guerra, como Josef Mengele, Adolf Eichmann e Klaus Barbie após a Segunda Guerra Mundial. E como esse fato deu o mote para aparição de obras literárias sobre fantásticas aventuras de "caçadores de nazistas" em busca do paradeiro dessas pessoas. Para tanto, na primeira parte do artigo abordaremos a fuga desses nazistas para a América Latina, para em seguida analisarmos algumas obras literárias de autores que se autointitularam como caçadores de nazistas.
\end{abstract}

Palavras-chave: IV Reich. Nazismo. América Latina. Imaginário.

Doutorando em História pela Universidade Federal do Paraná. Brasil. markosmeinerz@gmail.com 


\title{
OPERATION ODESSA: THE FLIGHT OF NAZI WAR CRIMINALS TO LATIN AMERICA AFTER WORLD WAR II AND THE NAZI HUNTERS
}

\begin{abstract}
This article aims to analyze why Latin America, especially Argentina, was the region of the world that harbored the most Nazi war criminals-for example, Josef Mengele, Adolf Eichmann and Klaus Barbie-after World War II. It also aims to analyze how this fact has set the tone for the appearance of literary works about the fantastic adventures of "Nazi hunters" seeking the whereabouts of those individuals. For this purpose, in the first part of the article we will address Nazis' escape to Latin America. Next, we analyze some literary works by authors who called themselves Nazi hunters.
\end{abstract}

Keywords: Fourth Reich. Nazism. Latin America. Imaginary.

\section{A gUERRA ACABOU: DESTINO AMÉRICA DO SUL}

$A$ pós a Segunda Guerra Mundial, os países aliados, Inglaterra, EUA, União Soviética e França, formaram um tribunal internacional com a finalidade de como 0 Tribunal de Nuremberg, nome da cidade que acolheu o júri, localizada na Alemanha, ao norte do estado da Baviera. Muitas pessoas que possuíam seu passado relacionado ao governo nazista viram suas situações se tornarem extremamente complicadas, principalmente os cientistas, ex-soldados e técnicos militares.

Alguns membros desses grupos preferiram fugir da Alemanha ao invés de enfrentar 0 tribunal e serem possivelmente condenados. Porém, não foram os únicos a deixar o país. Devido à insegurança jurídica e política e em função da fome e destruição provocadas pela guerra, após 1945 muitos alemães que não faziam parte dos grupos citados acima também deram adeus à Alemanha (MEDING, 1998, p. 11).

Segundo a "Comisión para el Esclarecimiento de las Actividades del Nazismo en Argentina" - CEANA - criada em 1997, e destinada a investigar a extensão e profundidade dos vínculos nazistas do país durante e após a Segunda Guerra Mundial, um dos países que mais recebeu essas pessoas foi a Argentina durante o governo de Juan Domingo Perón. Depois de desembarcarem no novo continente, os imigrantes alemães espalharam-se por outros países da América do Sul como o Brasil, Paraguai, Bolívia e Uruguai. 
Durante dois anos de pesquisa, 1997 a 1999, o grupo CEANA publicou quatro informes totalizando cerca de duas mil páginas. As principais fontes de investigação do grupo estão em arquivos do exército, marinha, aeronáutica, arquivos do Ministério do Interior da Argentina, da Alemanha, Espanha e Itália (MEDING, 1998, p. 12). Cabe destacar que em 1997, a maioria dos arquivos governamentais argentinos foram abertos pela primeira vez para pesquisadores, e os integrantes do CEANA foram um dos primeiros a ter acesso a essas fontes. Já em 1998, o grupo publicou o seu primeiro informe com os avanços das pesquisas realizadas, relatando as barreiras e dificuldades encontradas para a realização de tal.

Nesse primeiro informe, o grupo analisa a razão de a Argentina ser o país que mais recebeu criminosos de guerra nazistas, buscando perceber a relação do país com os alemães desde a Primeira Guerra Mundial, passando pela Segunda Guerra, até o governo de Juan Domingo Perón, entre 1946 a 1955.

Segundo Holger Meding, pesquisador do CEANA, antes da Primeira Guerra Mundial, a Argentina já era destino de imigrantes oriundos dos países da Europa Central:

A Argentina como país de imigração tem uma larga tradição em atrair pessoas da Europa central. 0 fluxo de imigrantes procedentes dos países de língua germânica para a Argentina, a partir dos anos sessenta do século passado (1860), experimentou várias fases: fugindo das crises do velho continente, das leis anti-socialistas, do autoritarismo imperial, das consequências do Tratado de Versalhes, da crise econômica mundial (MEDING, 1998, p. 10).

Durante a Primeira Guerra Mundial, o país permaneceu neutro até o fim do conflito, mesmo sob pressão do governo inglês e norte-americano. Segundo Meding, esse fato fez com que a diplomacia entre Argentina e a Alemanha se tornasse bastante consistente, e logo após o término da guerra, o governo argentino atraiu milhares de imigrantes alemães para as suas terras (MEDING, 1998, p. 10).

No período da Segunda Guerra Mundial, a Argentina manteve-se neutra por quase todo o conflito, somente cortando relações diplomáticas com a Alemanha devido às pressões do governo inglês e norte-americano, em janeiro de 1944. Posteriormente, em 1945, o país declarou guerra à Alemanha (MEDING, 1998, p. $10)$. 
No decorrer do conflito, o governo argentino manteve relações secretas com 0 alto escalão da Alemanha Nazista de Adolf Hitler. Segundo o historiador Uki Goñi, em uma entrevista cedida ao jornalista Ariel Palácio e publicada no site do jornal stadão $^{2}$ no primeiro dia de setembro de 2009, o principal personagem de ligação entre o país e o III Reich foi Juan Carlos Goyeneche, líder dos nacionalistas católicos da Argentina, que viajou dezenas de vezes à Alemanha, onde se reunia com o chanceler Joachin Von Ribbentrop, o líder das SS Heinrich Himmler, e outros líderes fascistas europeus como Mussolini, Franco e Salazar.

Outro enlace entre os dois países, afirma Goñi, foi Osmar Hellmuth, um germano-argentino enviado como emissário especial para negociar com Hitler 0 apoio argentino em troca de armas. Mas Hellmuth foi preso pelos britânicos no meio do caminho, e permaneceu assim até o fim da guerra, impedindo as conversações oficiais de uma possível aliança argentina-germânica.

Goñi afirma também que esses contatos demonstram que Hitler e seus assessores já pensavam na extensão de seu domínio ou influência na América do Sul, principalmente para fazer frente à influência que os EUA possuíam sobre 0 continente. Seu instrumento seria Juan Domingo Perón (1895 - 1974), na época secretário de Guerra, e a eminência parda do poder na Argentina. Perón já vinha estabelecendo contatos e colaborações com o III Reich desde o início da Segunda Guerra Mundial.

Em 1941, um mapa chegou a ser encontrado em um táxi que se envolveu num acidente de trânsito na cidade do Rio de Janeiro. 0 mapa mostrava a redistribuição territorial da América do Sul a ser imposta pela Alemanha depois de sua vitória. 0 subcontinente seria reduzido a apenas quatro países e uma colônia, todos sob proteção alemã, a saber:

- Brasil;

- Argentina, que absorveria o Uruguai, Paraguai, toda a parte baixa da Bolívia e um corredor ao Pacífico;

- Chile, incluindo o restante do Peru e da Bolívia;

- Nova Espanha, formada pela Colômbia, Venezuela e Equador, mais o Panamá;

- As Guianas unificadas como colônia francesa.

\footnotetext{
${ }^{2}$ A entrevista pode ser visualizada no site: http://blogs.estadao.com.br/ariel-palacios/peron-e-oterceiro-reich
} 
Posteriormente, descobriu-se que havia sido forjado pela inteligência britânica. Mas segundo Goñi, apesar da falsidade do mapa, ele ilustra bem como Hitler queria reconfigurar o mundo. Ele também duvida que os alemães pensassem seriamente em uma invasão da América do Sul, mas fizeram o possível para estimular o surgimento de governos favoráveis ao Reich, de forma a incomodar os EUA.

Em 1945, com o final do conflito e a derrota da Alemanha, os possíveis planos traçados pelo III Reich para a América Latina não saíram do papel. Mas nem por isso as relações da Argentina com os nazistas terminaram. Em 1946, Perón foi eleito presidente da Argentina, e com ele, iniciou-se uma grande campanha de imigração para atrair para a Argentina cientistas, técnicos, engenheiros, instrutores militares entendidos em aviões e armamentos, que participaram do governo nazista. 0 objetivo de Perón era transformar o país em uma superpotência na América Latina, e para isso queria contar com as tecnologias desenvolvidas pelos nazistas no setor bélico e industrial.

Um atrativo a mais para que os alemães escolhessem a Argentina como novo "lar" era a forma como Perón governava o país, tanto quanto suas concepções políticas e ideológicas. Nesse aspecto, Meding destaca que:

0 regime autoritário peronista e sua frente ideológica contra 0 comunismo e contra 0 capitalismo, um presidente com aberta simpatia com os alemães, exercia além das fronteiras argentinas uma atração mágica sobre aqueles que viram desvanecer seus ideais no fogo da Segunda Guerra Mundial (MEDING, 1998, p. 11).

A esses grupos, uniram-se as pessoas que foram procuradas pelos aliados como criminosos de guerra, pois devido aos monstruosos delitos contra toda a humanidade, dificilmente poderiam esperar obter perdão dos novos governantes da Europa. Para todos, a Argentina se apresentava como um refúgio, um abrigo seguro.

Perón chegou a admitir sua admiração pelas ideias do fascismo, e muito depois, nos anos de 1970, ainda criticava o Julgamento de Nuremberg, que definia como sendo uma infâmia. Dizia que havia tentado resgatar o máximo de alemães do tribunal. Objetivo que realmente conseguiu.

0 governo argentino organizava e pagava todo 0 processo de migração dessas pessoas. Organização que envolvia várias entidades: a Igreja Católica 
oferecia alojamento, coordenação e transporte; a Cruz Vermelha procurava a documentação e os consulados argentinos concediam o visto após uma entrevista com as autoridades da imigração em Buenos Aires (MEDING, 1998, p. 11). Pesquisadores do grupo CEANA (1998) sustentam que antes do fim da guerra, o governo de Perón entregou a embaixada alemã oito mil passaportes argentinos e cem mil cartões de identidade devidamente assinados e carimbados, sem fotos ou impressões digitais.

A operação toda de salvamento ou resgate de criminosos de guerra nazista, de técnicos, engenheiros e cientistas para a Argentina ficou conhecida como Operação Odessa.

\section{A OPERAÇÃo ODESSA - ORGANIZAÇÃO DOS EX-MEMBROS DA SS}

Em 1972, Frederick Forsyth, escritor e jornalista inglês, publicou o romance intitulado $O$ Dossiê Odessa, no qual narra a história de um jornalista "free-lancer" alemão-ocidental e as implicações que ele vai tendo com nazistas na década de 1960. Na obra, Forsyth apresenta logo no prefácio que o significado de "Odessa" é uma abreviação para "Organisation Der Ehemaligen SSAngehorigen" que significa, em resumo, "Organização dos Ex-Membros da SS", responsável por proteger os antigos nazistas dos julgamentos por crimes contra a humanidade e, em último grau, de livrar o mundo de uma ameaça causada pelos judeus. Essa organização é o tema central do livro que se baseia numa conspiração da Odessa para a destruição do Estado de Israel.

No romance, Forsyth constrói um suspense protagonizado por Peter Miller, repórter alemão "free-lancer" que se empenha em fazer uma reportagem sobre um antigo oficial da SS que foi visto nas ruas de Hamburgo, Alemanha. No entanto, tudo fica mais difícil no momento em que descobre que seu alvo é apenas uma peça em um jogo muito maior. Tudo começa quando Miller ouve a notícia da morte do presidente Kennedy no rádio de seu carro, fazendo-o parar no caminho que tomava para Hamburgo. 0 tempo perdido na estrada foi responsável por criar 0 momento perfeito, quando Miller vê uma ambulância em alta velocidade, e decide acompanhar o veículo na tentativa de uma ótima reportagem.

Aparentemente Miller teria perdido tempo, já que o caso era apenas mais o suicídio de um homem idoso, um tal de Salomon Tauber. Seria isso se não fosse o fato do homem morto ter sido um antigo prisioneiro do campo de concentração de Riga, Letônia, e, em seu diário, ter narrado o encontro com 0 comandante do campo há apenas uns dias antes do suicídio: 0 capitão Roschmann. 
Após ler o diário de Tauber, Miller decide ir atrás do oficial para entregá-lo às autoridades. Além disso, poderia ser o tema de uma nova e lucrativa reportagem. Várias indisposições começam a aparecer com as autoridades responsáveis por manter registros sobre os nazistas procurados. Roschmann é apenas uma das peças, e a Odessa já começava a ter conhecimento da intromissão de Miller. Com impasses, Miller procurou dados sobre os refugiados de Riga no centro comunitário judaico de Munique, onde finalmente ele encontra um exprisioneiro daquele campo que o introduz em uma espécie de sociedade secreta formada por judeus que sofreram nos campos de concentração. 0 objetivo dessa sociedade é encontrar e matar nazistas. A partir deste momento Miller é treinado para se comportar como um "camarada" da SS, para que possa se infiltrar na Odessa e descobrir quem são os membros da organização. "É um plano muito arriscado, o que torna evidente que suas intenções no caso vão muito além de uma simples reportagem." (FORSYTH, 1982, p. 53).

Porém, a organização Odessa extrapola a ficção de Forsyth, pois a referida entidade realmente existiu. De fato, na década de setenta as atividades de resgates e transporte de criminosos de guerra nazistas, principalmente para a Argentina, por esta organização, já eram conhecidas de muitos. Para uma análise mais detalhada sobre essa operação, citamos o autor já mencionado anteriormente, Uki Goñi, que em sua obra, A verdadeira Odessa, publicada em 2004, efetua uma investigação minuciosa que revela como Juan Perón armou uma vasta rede de agentes internacionais destinada a resgatar centenas de colaboradores do III Reich.

Goñi (2004) descreve os mecanismos de fuga, analisa o antissemitismo da elite argentina e documenta os primeiros contatos entre Perón e os nazistas. $A$ verdadeira Odessa reconstitui o processo desde a chegada de agentes do serviço secreto de Himmler a Madri, em 1944, com o objetivo de preparar rotas que permitissem a fuga dos nazistas derrotados. Em 1946, esta operação foi transferida para Buenos Aires, estabelecendo-se a partir da Casa Rosada e estendendo seus tentáculos até a Escandinávia, Suíça e Itália. Tal pesquisa fundamentou-se em arquivos inéditos do Serviço Secreto norte-americano, em documentos particulares europeus descobertos nos últimos anos, e em entrevistas com envolvidos nesses processos (GOÑI, 2004).

Foram duas as principais rotas utilizadas pelos criminosos de guerra para chegar à Argentina: a Rota dos Conventos e a Conexão Suíça. Segundo Uki Goñi, o maior número de refugiados que logrou chegar à Argentina utilizou a chamada rota dos conventos, que contava com a ajuda do Vaticano que tinha medo do 
avanço comunista na Europa. Perón confiou essa rota ao sacerdote José Clemente Silva, que tinha como "missão" organizar o embarque de " 4 milhões de europeus para a Argentina, à razão de 30 mil por mês, com a finalidade de potenciar a revolução econômica e social que Perón havia concebido para seu país" (1998 apud COSTA, 2004, p. 455).

José Clemente ainda recebeu outro encargo: ocupar-se do transporte de personalidades especiais, carentes de documentação. Essa tarefa o pôs em contato, na Itália, com o ex-espião Reinhard Kops e com o bispo Alois Hudal, reitor da igreja alemã Santa Maria dell'Anima, em Roma, que integravam a rede. 0 bispo Hudal ${ }^{3}$ conseguiu por meio da rota dos conventos, trazer centenas de criminosos que deveriam ser julgados por atos cometidos durante 0 regime nazista e encaminhá-los à Argentina. 0 esquema era relativamente simples: Kops trabalhava em sintonia com o consulado argentino em Gênova por intermédio de um tirolês, Franz Ruffinengo, engajado como secretário da Comissão Argentina de Imigração pelo fato de falar alemão e poder facilitar os trâmites burocráticos. Emitidas as autorizações de entrada em Buenos Aires, e obtidos os passaportes da Cruz Vermelha, "o consulado apunha 0 seu visto e a preciosa carga embarcava tranquilamente nos navios da linha Dodero" (1998 apud COSTA, 2004, p. 456). Segundo Goñi, dentre os personagens mais célebres que fugiram por essa rota, encontram-se Klaus Barbie, conhecido como o "Carniceiro de Lyon", que permaneceu pouco tempo em Buenos Aires antes de se fixar na Bolívia, Adolf Eichmann que se refugiou em terras argentinas e Franz Stangl que se fixou no Brasil (1998 apud COSTA, 2004, p. 457).

A outra rota de fuga utilizada pelos nazistas para chegar à Argentina, ficou conhecida como "Conexão Suíça". Na capital desse país, Berna, afirma Goñi, foi estabelecido o centro das operações de resgate dessas pessoas, e de lá eram traçadas as rotas de escape a partir da Alemanha ocupada pelos aliados. Josef Mengele, por exemplo, foi resgatado com a ajuda dessa organização. Outros criminosos, como o Dr. Gerhard Bohne, que era administrador do programa de eutanásia de Hitler; Erich Priebke, implicado na matança das Fossas Ardeatinas em Roma, e Josef Schwammberger, responsável pelas matanças de judeus na Polônia, também receberam ajuda dos agentes de Perón por essa rota (1998 apud COSTA, 2004, p. 462).

\footnotetext{
${ }^{3}$ Para analisar mais detalhadamente o papel que o bispo Hudal teve na fuga de criminosos de guerra nazista para várias regiões do mundo, ver: Sanfilippo (1999).
} 
Nesse contexto, criminosos de guerra, técnicos, engenheiros e cientistas fugiram para a Argentina com passaportes e documentos falsos, e todo o sistema citado ajudava-os a saírem da Europa sem serem percebidos, encontrando nas terras argentinas e depois pelo resto da América do Sul uma nova Heimat ${ }^{4}$. Estima-se que cerca de 100 mil nazistas fugiram da Europa para a Argentina entre 1945 a 1955, dentre eles vários criminosos de guerra que estariam usufruindo um "bappy retirement" (aposentadoria feliz) no país 5 (MEDING, 1998).

Apesar dessa cifra, a migração de criminosos nazistas para a Argentina não passava de um vago rumor até meados da década de 1960, quando o sequestro de um dos responsáveis pela "solução final" - Adolf Eichmann - num subúrbio de Buenos Aires, por um comando israelense, trouxe à tona 0 passado recente do país.

Segundo a pesquisadora do grupo CEANA, Carlota Jackisch, Adolf Eichmann, que foi o responsável de implantar a assim chamada Solução Final da questão judaica, ingressou na Argentina em 14 de julho de 1950, proveniente de Genoa da Itália. Teria viajado a bordo do vapor "Giovanna C", sendo titular do passaporte $n^{0} 100.940$ outorgado pelo Comitê Internacional da Cruz Vermelha, com o nome de Ricardo Klement. Eichmann obteve em Tucumán a cédula de identidade $\mathrm{N}^{0} 341.952$, trabalhando nessa província para a Companhia Argentina de Projetos e Realizações Industriais (CAPRI) entre $1^{\circ}$ de outubro de 1950 até 30 de abril de 1953. Posteriormente, mudou-se para a província de Buenos Aires, onde conseguiu a cédula de identidade $\mathrm{N}^{0} 1.138 .538$, sendo seu lugar de trabalho a fábrica metalúrgica Efeve (JACKISH, 1999, p. 86).

Já Josef Mengele, formado em Filosofia e em Medicina; Tenente Coronel das SS e médico do campo de concentração de Auschwitz era procurado por seus experimentos com os prisioneiros dos campos. Ingressou no país em 20 de junho

\footnotetext{
${ }^{4}$ A palavra Heimat, se origina de Heim, lar em português. Como tal sugere uma realidade construída na qual os componentes essências são um espaço geográfico concreto e visível, organizado numa paisagem familiar na qual se abriga a tradição cultural. À percepção da Heimat incorporam-se invariavelmente a moradia, das Haus, as Heim, o estar em casa, der Hof, o miniterritório em que se concretizam a vida e as relações familiares. Significa, portanto, o espaço e 0 mundo comunal em que a pessoa nasce, cresce e se torna adulta e no qual se enraíza e com 0 qual desenvolve relações existenciais permanentes. Assim, uma pessoa pode construir a sua Heimat em qualquer parte do mundo e a América do Sul seria o novo lar, a sua nova Heimat, desde que mantivessem as tradições alemãs (MAUCH, 1994, p. 47).

${ }^{5}$ É interessante ressaltar que nem todos os fugitivos alemães, por mais "nazistas" que fossem, não podem ser considerados, obrigatoriamente, criminosos. Alguns deles eram apenas partidários ou simpatizantes das ideias nazistas.
} 
de 1949 com passaporte da Cruz Vermelha Internacional No 100.501 com o nome de Helmut Gregor, com o qual obteve a cédula de identidade da Polícia Federal No 3.940.484. No mês de novembro de 1956, apresentou sua certidão de nascimento legalizada e certificada pela embaixada da República Federal da Alemanha em Buenos Aires, solicitando a retificação do seu nome. Desta maneira obteve a cédula de identidade da Polícia Federal Argentina, com o mesmo número que a anterior com o nome de Mengele, nascido em Günsburg, província de Baviera, em 16 de março de 1911. Em 9 de outubro de 1959 a Alemanha solicitou a captura de Mengele. Em 18 de janeiro de 1960 foi requisitada sua extradição (JACKISH, 1999, p. 89).

Jackisch ainda nos mostra um grande número de pessoas que foram consideradas criminosas de guerra, e que imigraram para a Argentina após a guerra. Segundo a autora temos: Ludolf Hermann Alvensleben, Klaus Barbie, Franz Stangl, Gerhard Bohne, Kurt Christmann, Hans Fischbock, Erwin Fleiss, Fridolin Guth, Hans Friedrich Heffelmann, Bernhard Heilig, José Janco, Ekart Krahmer, Walter Kutschmann, Fritz Lantschner, Erich Muller, Erich Priebke, Friedrich Rauch, Walter Rauff, Eduard Roshmann, Josef Schwammberger, Francisco Votterl e Guido Zimmer; só para citar alguns de uma lista de mais de 180 nomes (JACKISH, 1999, p. 90). Algumas dessas pessoas foram procuradas e caçadas, especialmente aquelas com um maior renome, como Adolf Eichmann, Josef Mengele e Klaus Barbie.

Uma das pessoas que ficou mais conhecida por "caçar" tais personagens foi Simon Wiesenthal, que dedicou mais de cinquenta anos de sua vida em busca de justiça aos milhões de judeus, homossexuais, dissidentes políticos e ciganos mortos em campos de concentração durante a guerra.

Wiesenthal, judeu, nasceu na cidadezinha de Buczacz, vizinha a Leopoli, pertencia à Polônia, parte do Império Austro-Húngaro. A região foi invadida pelas tropas alemãs em 1939 e depois entregue ao governo da União Soviética, com quem a Alemanha tinha um acordo de guerra. Passou por 13 campos de concentração dos quais inúmeras vezes fugiu, sendo capturado posteriormente e torturado várias vezes. No pós-guerra, dedicou-se a capturar os criminosos nazistas espalhados pelo mundo. Falava que não se tratava de vingança, mas sim de justiça para com o seu povo. Foi responsável pela prisão de mais de mil criminosos nazistas no pós-guerra, dentre eles o mais famoso, Adolf Eichmann 
que foi capturado na Argentina. Wiesenthal faleceu aos 96 anos, em 20 de setembro de 2005, em Viena ${ }^{6}$.

Wiesenthal não foi o único que se dedicou a procurar os criminosos de guerra que fugiram da Europa após o encerramento do conflito. Pelo menos é 0 que indica o campo literário, no qual encontramos várias obras que narram a perseguição dos mais célebres nazistas como Martin Bormann, Josef Mengele e até mesmo Adolf Hitler, por vários cantos do planeta.

A seguir, analisamos mais detalhadamente algumas obras literárias que representam as histórias desses caçadores de nazistas e que possuem como temas principais: a caça a nazistas pelas terras latino-americanas, a denúncia de uma conspiração para a formação do IV Reich na América Latina e que Hitler não teria se suicidado no final da guerra, mas sim se refugiado na Argentina.

\section{Os CAÇADORES de NAZISTAS}

Em 1977, o austríaco Erich Erdstein (1977) publicou no Brasil o livro "Renascimento da Suástica no Brasil", no qual relata as mais incríveis histórias enquanto caçava o "anjo da morte", Josef Mengele, pela América do Sul, ao mesmo tempo em que denunciava a existência de uma conspiração para a formação do IV Reich no continente.

Judeu Austríaco, Erdstein refugiou-se no continente em 1939 devido à perseguição nazista. No Brasil, em 1960, passou a trabalhar como tradutor da DOPS, em Curitiba. No seu livro, "o caçador de nazis mais receado no mundo" relata suas aventuras desde sua fuga às pressas de Viena, Áustria, para a América do Sul em 1938 quando tinha 18 anos de idade até a morte de Josef Mengele levada a efeito pelo próprio Erdstein.

Depois das mais extraordinárias aventuras "a la James Bond" em busca do "anjo da morte" pelo continente, a narrativa tem seu desfecho na região da Tríplice Fronteira entre o Brasil, Paraguai e Argentina, onde Erdstein, ao saber que Mengele iria cruzar o rio Paraná a bordo de um barco, adiantou-se e armou uma emboscada, conseguindo aprisioná-lo. Ao levá-lo de barco para a Argentina, foram interceptados por uma embarcação da marinha paraguaia:

\footnotetext{
${ }^{6}$ Biografia de Simon Wiesenthal no site: http://educacao.uol.com.br/biografias/ult1789u619.jhtm..
} 
Assim que a lancha ficou mais perto, Mengele disparou rumo à liberdade, a segurança. Para! Stop! - Gritei. Dois soldados paraguaios pularam para a barcaça a fim de pegar os dois alemães. Levantei a arma e fiz quatro disparos contra Mengele. Os tiros atingiram-no no peito e do lado. Virou-se para mim, olhou-me com uma expressão de surpresa e tornei a disparar. Desta vez atingi-o em cheio na garganta. Seu corpo estremeceu violentamente e caiu da barcaça, de cabeça dentro da água. Seus pés ficaram presos em algumas cordas que estavam no deck; ficou dependurado com a cabeça tocando a água. Os paraguaios, que tinham recuado quando comecei a atirar, agarraram 0 outro alemão e pularam de volta para a sua lancha. Tornei a disparar e vi o segundo prisioneiro cambalear e agarrar a perna. Ouvi um grito que vinha do outro lado da barcaça, virei-me e vi um imenso navio patrulha com uma bandeira azul e branca da Argentina hasteada no mastro. Os argentinos gritaram na direção dos paraguaios, que replicaram em língua guarani. Tiros passaram zunindo junto a minha cabeça e, por alguns minutos, houve um tumulto de gritos e disparos. Os paraguaios, vendo que nada podiam fazer contra as armas do barco argentino, deram cobertura a dois dos seus homens que arrancaram Mengele da água enquanto a lancha começava a se afastar. Seu corpo estava inerte e vi que estava morto. Tinha ficado na água durante cinco minutos, no mínimo [...]. Vi diante de mim o corpo de Mengele mergulhado dentro da água. Um nazista morto. Mas que importava isto? Um nazista nunca morre. Aparecerá amanhã, novamente, com um rosto diferente e um nome diverso, talvez falando uma língua diferente, mas com as mesmas antigas ideias. Senti-me, de repente, cansado demais (ERDSTEIN, 1977, p. 194).

0 dramático desfecho apresenta a morte de Mengele e as razões pelas quais Erdstein não poder apresentar a "prova", ou seja, o corpo do mesmo. Todavia, na década de 1980, após a exumação de um cadáver no cemitério do Embu, São Paulo, constatou-se que se tratava de Mengele. Este havia morrido em 1979, vítima de um ataque cardíaco enquanto nadava no mar em Bertioga, litoral paulista (FOLHA DE SÃO PAULO, 31 de out. 2010).

Semelhante a Erdstein, Ladislas Farago também se apresenta como caçador de nazistas. Em 1974, Farago, escritor húngaro radicado nos Estados Unidos da América, publicou o livro "Aftermath. Martin Bormann and the Fourth Reich" (Consequências. Martin Bormann e o IV Reich). Com 479 páginas, o livro alcançou grande vendagem chegando a ser publicado em língua alemã em 1975, 
sob o título de Scheintot (Aparentemente Morto), além de, no mesmo ano, ser publicada a segunda edição, sob o título "Aftermath: The Most Daring Manhunt of our Time. The final Search for Martin Bormann" (Consequências. A Mais Ousada Perseguição do Nosso Tempo. A Busca Final de Martin Bormann). No livro, 0 autor narra suas aventuras enquanto seguia o rastro de Martin Bormann pela América Latina ao mesmo tempo em que também denuncia a possivel formação do IV Reich pela região, que seria comandado pelo "braço direito" de Hitler:

Baseado em entrevistas (algumas das quais fizeram parte de manchetes em todo o mundo), documentos e arquivos secretos, Aftermath é o primeiro registro real de uma notável e bem sucedida conspiração mundial, que teve início nas ruínas flamejantes da derrotada Alemanha nazista e terminou em um outro continente em uma nova hierarquia nazista, com 0 evasivo gran fugitivo, Martin Bormann, na sua liderança (FARAGO, 1974, p. 1).

No livro, o autor apresenta uma série de documentos que comprovariam que Bormann estaria vivo. Em um suposto documento que, segundo Farago, foi retirado da Polícia Federal da Argentina, temos a descrição da movimentação e das atividades que Martin Bormann realizou na América do Sul. Segundo um desses documentos,

Bormann passou pela Argentina, usando vários pseudônimos, como 0 de 'Juan Gomez' o seu preferido [...] 1952: Bormann era residente dos Estados Unidos do Brasil, vivia no estado de Mato Grosso e Santa Catarina, ele também fez rápidas viagens para diversos lugares do Paraguai, Valdivia no Chile, Bariloche e Ascochinga na Argentina. Na província de Córdoba, ele esteve em contato com o comando central da organização Araña (Aranha), uma organização [designada] a sustentar e reviver a ideologia do Nacional-Socialismo... 1958-1959: Bormann localizado em uma isolada fazenda perto de Curitiba, Brasil... 1961: Bormann se encontra com Mengele no clube noturno Ali Baba em Assunção, Paraguai (FARAG0, 1974, p. 270).

Podemos interpretar que Farago utiliza esses documentos para tentar provar que Martin Bormann estaria vivo, pois, se o mesmo estivesse morto, toda a 
sua história "cairia por terra". E o uso desses documentos foi uma das maneiras que ele utilizou para legitimar o seu discurso.

0 autor (e muitos outros) não crê na versão de que Bormann tenha morrido em Berlim, em 1945. Farago teria até mesmo se encontrado com Bormann:

Eu o encontrei em um pequeno hospital, que tinha apenas uma dúzia de camas e um quarto individual improvisado para ele, em que dispunha de um excelente e dedicado cuidado de quatro irmãs da Ordem Redentorista. Quando fui levado para o seu quarto, que concordamos ser uma visita de cinco minutos (sem perguntas feitas e, certamente, sem respostas dadas), eu vi um velhinho em uma cama grande com lençóis recém lavados, com a cabeça apoiada por três grandes almofadas, olhando para mim com os olhos vagos, murmurando palavras para si mesmo, erguendo a voz uma única vez, e disse, não só com alguma ênfase, mas com um vigor que me surpreendeu, "você não vê que eu sou um homem velho? Então por que você não me deixa morrer em paz?" (FARAG0, 1974, p. 431).

Outro que se dedicou a procurar Bormann durante as décadas de 1960 e 1970 foi 0 inglês Charles Whiting. Na sua obra - À Caça a Martin Bormann de 1977, o autor narra como investigou o paradeiro do "bomem das sombras" pela Ásia e Europa, averiguando pistas, entrevistando testemunhas e apresentando os mais diversos homens que se empenharam a procurar Bormann.

Minha caça particular a Martin Bormann levou-me a dois continentes e seis países. É uma história composta de enganos e traições, pulos de um ponto a outro do globo, sexo à la nazi, pinceladas de sordidez e high-society, personagens extraordinários envolvidos, e todos os toques excêntricos obrigatórios nas histórias de detetives desde a invenção de Sherlock Holmes. No entanto, não se trata aqui de ficção. Tudo são fatos. E sempre muito reais. Eis a história da maior caçada humana de todos os tempos e do maior enredo detetivesco que 0 mundo já conheceu: a caça a Martin Bormann (WHITING, 1977, p. 7).

Whiting era escritor de romances e historiador militar, que entre os anos de 1954 e 2007 escreveu cerca de 350 livros, incluindo setenta títulos de "não-ficção" 
que abordam temas variados do serviço de inteligência nazista aos regimentos britânicos durante a Segunda Guerra Mundial. Seu primeiro romance - The Frat Wagon (0 vagão da fraternidade) foi escrito em $1954^{7}$.

Na obra À Caça a Martin Bormann, o autor nós apresenta uma cronologia das notícias sobre o paradeiro de Bormann:

1947: Bormann em Sidnei. 1947: Bormann no Egito. Março de 1947: 0 Serviço Secreto americano procura Bormann na Espanha. Julho de 1947: Chegam rumores à Europa de que Bormann está vivendo ao pé dos Andes. Novembro de 1949: Bormann "visto" em Munique. Abril de 1950: Um jornal dinamarquês informa que Bormann está na África do Sul. Outubro de 1950: 0 emigrante alemão Hesslein informa que Bormann está no Chile. 1958: Bormann "visto" no Equador. 1960: Bormann "visto" na Argentina. Abril de 1961: 0 Promotor Distrital Fritz Bauer, de Frankfurt, declara: "Bormann ainda está vivo". Maio de 1961: Bormann vive no Brasil. Novembro de 1961: Bormann agora está no Chile? Junho de 1962: Informa-se que Bormann fugiu da Alemanha num submarino alemão. Foi para a Argentina. Visita à Alemanha uma vez por ano. Março de 1964: Descoberto "túmulo" de Bormann no Paraguai (morto em fevereiro de 1959). Março de 1964: Simon Wiesenthal: "Bormann está vivo na América do Sul". Abril de 1964: 0 tcheco Jaroslav Dedic declara: "Enterrei Bormann em Berlim, em 1945". 1966: Bormann vivendo numa tribo de índios em Mato Grosso, no Brasil. 1967: Correm boatos sobre Bormann em Kolonie Waldner 555, na América do Sul. 13 de dezembro de 1971: 0 governo alemão desiste de procurar Martin Bormann (WHITING, 1977, p. 9).

Todavia, apesar do "encontro" e das várias notícias sobre o paradeiro de Martin Bormann, em abril de 1998 foi realizado um teste de DNA nos restos mortais encontrados em Berlim em 1972, que confirmou serem de Bormann, que morreu no final da Segunda Guerra Mundial (Revista Veja, 1998, p. 138). Já em abril de 1992 o argentino Juan José Velasco, que vendeu em 1972 os documentos sobre Bormann que Farago utilizou em seu livro, contou como 0 havia enganado, vendendo-lhe documentos falsos:

\footnotetext{
${ }^{7}$ Podemos observar algumas dessas obras no site: http://www.fantasticfiction.co.uk/w/charleswhiting.
} 
Eu havia estado com ele duas vezes em setembro e no princípio de dezembro de 1972 eu sabia que ele estava interessado em conseguir materiais sobre Bormann. Foi muito fácil fazer porque eu tinha papel timbrado. Só foi questão de inventar informes e colocar neles selos e códigos para que parecessem autênticos. Ele comprou todo o material. Na realidade, tudo parecia muito confiável (BURNSIDE, 2000, p. 563).

Após o encerramento do conflito, tanto os aliados ocidentais quanto os soviéticos se empenharam intensamente na busca por Martin Bormann, que terminou julgado e condenado pelo tribunal de Nuremberg - in absentia. Histórias, versões e teorias das mais absurdas e fantasiosas, ou ao contrário, prováveis, mas sem evidências, passaram a circular sobre o que teria acontecido com esse personagem que parece ser tão esquivo, dissimulado e poderoso. Pesquisadores das mais variadas tendências de diferentes países se dedicaram a essa investigação e, como vimos, mais de um, chegou a encontrá-lo vivendo tranquilamente em algum recanto agradável da América do Sul, ou até mesmo na China.

Mais do que qualquer outro, o desaparecimento de Martin Bormann deu lugar a especulações de toda a sorte, pois para além de um integrante da cúpula do Terceiro Reich, era líder do movimento nazista e muito mais: detentor dos segredos e planos traçados para o pós-guerra. Mas como vimos a sua vida se encerrou quando o Exército Aliado invadiu Berlim no primeiro dia de maio de 1945.

\section{CONSIDERAÇÕES FINAIS}

0 fato de que várias pessoas envolvidas com o nazismo, pelo menos as que ficaram mais conhecidas após o término da guerra devido às suas atividades relacionadas, principalmente, ao holocausto, como Adolf Eichmann e Josef Mengele, terem escapado do tribunal de Nuremberg e se refugiado em terras latino-americanas, deu o mote para a aparição das mais fantásticas e fantasiosas versões sobre suas pretensas atividades secretas com vista à formação do IV Reich no continente.

Interpretamos que o tema inscreve-se em um imaginário político e social e num clima psicológico de incerteza, insegurança e medo que se instaurou após a Segunda Guerra Mundial, de que o nazismo poderia se reestruturar em algum lugar do mundo. 
Verificamos isso numa vasta produção literária (encontramos mais de 20 livros nacionais e internacionais, produzidos desde a década de 1960 até os dias atuais) que possui como tema principal a relação dos imigrantes e descendentes alemães da América Latina, com a suposta formação do IV Reich por suas terras.

Além dos livros de Erdstein, Farago e Whiting, temos a obra do húngaro Ladislao Szabo, que logo após o término da Segunda Guerra, em 1947, publicou na Argentina a obra intitulada "Hitler esta Vivo" (SZABO, 1947). No livro, o autor declara que Hitler não estaria morto e que ele havia sido transportado secretamente para a Antártida por um comboio de submarinos alemães, e que de lá estaria planejando a reestruturação do $I V$ Reich na América Latina.

A partir de 1964, o escritor brasileiro Roberto Botacini publicou quatro livros que, em suma, falam sobre a fuga dos principais líderes nazistas para a América Latina e que o suicídio de Hitler não passaria de uma fraude, pois estaria na América Latina junto de seus subordinados. A primeira obra intitula-se "Onde estará Hitler?". No mesmo ano publicou o livro "Nazistas na América" e no ano seguinte "A fuga de Hitler". Em 1977 publicou "O nazismo sobrevive ao Terceiro Reich".

No ano de 2010, os autores argentinos Carlos De Napoli e Juan Salinas (2010), publicaram a obra "Ultramar Sul - A última operação secreta do Terceiro Reich”, no qual é narrada a fuga de Hitler, por meio do uso de um submarino, da Alemanha para a patagônia.

Em 2011, os britânicos Gerrard Williams e Simon Dunstan (2011) publicaram o livro "The Grey Wolf - The Escape of Adolf Hitler" (Lobo cinza - A fuga de Adolf Hitler). Os autores sustentam que Hitler escapou da Alemanha três dias antes de seu suposto suicídio. Hitler teria se instalado em mais de uma residência na Patagônia, com Eva e duas filhas. Viveria mais 17 anos, e teria morrido no dia 13 de fevereiro de 1962, aos 72 anos. A fuga teria sido articulada por Martin Bormann, da cúpula do poder nazista, que também teria escapado para a América do Sul. A fuga, sustentam os autores, contou com a anuência dos EUA, que deixaram os nazistas fugirem em troca de informações sobre tecnologia de guerra. Bormann teria manejado também a fortuna que foi entregue aos governos latino-americanos para que abrigassem os nazistas.

Em 2004, o jornalista argentino Abel Basti escreveu o livro intitulado "Bariloche Nazi"; em 2006 lançou o livro "Hitler en Argentina"; em 2010 publicou o livro "El Exílio de Hitler en Argentina"; e seu último livro de 2011, 
recebeu o título de "Los secretos de Hitler" ${ }^{\text {. }}$ Basti também sustenta a teoria de que Hitler fugiu para a Argentina e refuta a ideia de que ele teria se suicidado ao final da guerra.

Nessas obras temos a exacerbação de um fato ocorrido após o término da guerra, ou seja: ao denunciar que essas pessoas, que foram consideradas criminosas de guerra nazistas, estavam vivendo impunemente nas terras latinoamericanas, como muitos viveram, os autores retratam uma realidade, porém a ficcionam para tal objetivo. Fazem uso de personagens reais como Mengele, Bormann e Hitler como mote de livros sobre incríveis aventuras.

Como afirma David Lowenthal (1998), a diferença entre história e ficção reside no fato de que o escritor de ficção é "forçado a inventar personagens e acontecimentos, ou pensamentos e ações imaginárias para pessoas reais do passado". Enquanto para o historiador, "o seu ofício proíbem-no sabidamente de inventar ou de excluir algo que afete suas conclusões", ou seja:

Ao se denominar um historiador e a seu trabalho a história, ele escolhe que ela seja julgada pela exatidão, consistência interna e congruência com os registros remanescentes. E ele não se atreve a inventar um personagem, atribuir características desconhecidas ou incidentais aos personagens verdadeiros, ou ignorar características incompatíveis de modo a tornar sua narrativa mais inteligivel, porque não poderia esconder tais invenções daqueles que têm acesso aos registros públicos nem justifica-las quando descobertas (LOWENTHAL, 1998, p. 134).

As narrativas presentes nos livros de Erdstein e Farago, por exemplo, encaixam-se no estilo ficção-policial, em que os autores utilizam a fuga de nazistas para a América Latina como mote para livros ficcionais com personagens reais. Romantizam os fatos, interpretando-os de acordo com a história que querem contar.

Devemos então analisar o imaginário da formação do IV Reich na América Latina, traduzido em um discurso, como derivado de um complexo conjunto de práticas que 0 mantém em circulação e que não são imagináveis sem um contexto receptivo, ou até uma procura ansiosa por histórias desse tipo. Inclui-se nesse contexto todo o aparato cultural e científico que se dedica ao tema: os leitores, as editoras, os autores, os meios de comunicação e os historiadores. Como afirma

${ }^{8}$ Para verificar as obras de Abel Basti ver: http://www.barilochenazi.com.ar. 
João Fábio Bertonha (2007), na sociedade contemporânea tudo aquilo que se refere a conspirações tem vendagem garantida. Livros sobre a Opus Dei ou o assassinato de Kennedy, por exemplo, têm público cativo e representam parte substancial do movimento das livrarias. Do mesmo modo, tudo aquilo que se relaciona ao nazismo também atrai a atenção. Não espanta, assim, "como livros e revistas sobre conspirações nazistas, sobre 0 relacionamento do nazismo com 0 oculto e temas correlatos tenham tanto público no mundo todo e há muito tempo" (BERTONHA, 2007, p. 1). Podemos falar da existência de uma "indústria" voltada ao tema.

E essa "indústria" se aproveita da existência de um fascínio pelo oculto, curiosidade e do medo daquilo que parece insidioso e incontrolável, para, desde a década de 1940, lançar produtos e mais produtos que encontram compradores por todo o mundo, movidos por tais sentimentos.

\section{REFERÊNCIAS}

BERTONHA, João Fabio. Nazismo, ocultismo e conspirações. História Unisinos, São Leopoldo, v. 11, n. 3, p. 381-384, 2007.

BURNSIDE, Patrick. El escape de Hitler. Buenos Aires: Planeta, 2000.

COMISIÓN PARA EL ESCLARECIMIENTO DE LAS ACTIVIDADES DEL NAZISMO EN ARGENTINA - CEANA Primer informe de avance. Buenos Aires, Argentina, mar. 1998.

COSTA, Sergio Correa. Crônicas de uma guerra secreta. Rio de Janeiro: Record, 2004.

DE NAPOLI, Carlos; SALINA, Juan. Ultramar Sul: a última operação secreta do Terceiro Reich. Rio de Janeiro: Civilização Brasileira, 2010.

ERDSTEIN. Erich; BEAN, Bárbara. Renascimento da Suástica no Brasil. São Paulo: Circulo do Livro, 1977.

FARAGO, Ladislas. Aftermath: Martin Bormann and the Fourth Reich. New York: Simon and Shuster, 1974.

FARAGO, Ladislas. Aftermath: the most daring manhunt of our time. The Final Search for Martin Bormann. New York: Simon and Schuster, 1975.

FARAGO, Ladislas. Scheinot. Hamburg: Hoffmann and Campe Verlag, 1975. 
FORSYTH, Frederick. O Dossiê Odessa. São Paulo: Abril Cultura, 1982.

GOÑI, Uki. A verdadeira odessa. Rio de Janeiro: Record, 2004.

JACKISH, Carlota. Cuantificación de criminales de guerra según fuentes Argentinas. In: CEANA. Comisión para el Esclarecimiento de las Actividades del Nazismo en Argentina. Informe Final. Argentina, 1999.

LOWENTHAL, David. Como conhecemos o passado. In: Projeto História, São Paulo, n. 17, p. 63-201, nov. 1998.

MAUCH, Cláudia. Os alemães no sul do Brasil. Canoas: Ed. ULBRA, 1994.

MEDING, M. Holger. Cuantificacion de criminales de guerra segun fuentes alemanas y austríacas. In: CEANA. Comisión para el Esclarecimiento de las Actividades del Nazismo en Argentina. Primer informe de avance. Argentina, 1998.

PALÁCIOS, ARIEL. Peron e o terceiro Reich. 2009. Disponível em: $<$ http://blogs.estadao.com.br/ariel-palacios/peron-e-o-terceiro-reich $>$. Acesso em: 8 jan. 2013.

SANFILIPPO, Matteo. Los papeles de Hudal como fuente para la historia de la migración de alemanes y nazis después de la Segunda Guerra Mundial. Estudios Migratorios Latinoamericanos, v. 14, n. 43, p. 185-210, 1999.

SZABO, Lasdilao. Hitler está vivo. Argentina: Tabano, 1947.

WHITING, Charles. À caça de Martin Bormann. Rio de Janeiro: Civilização Brasileira, 1977.

WILLIAMS, Gerrard; DUNSTAN, Simon. Grey Wolf: the escape of Adolf Hitler. United Kingdom: Sterling, 2011

WIESENTHAL, Simon. Biografias. Disponível em: $<$ http://educacao.uol.com.br/biografias/ult1789u619.jhtm>. Acesso em: 21 jan. 2010.

NINI0, Marcelo. Mossad descobriu Mengele no Brasil, mas não o deteve. Folha de São Paulo, São Paulo, 31 de out. 2010. Disponível em: http://www1.folha.uol.com.br/fsp/poder/po3110201002.htm

GOMES, Laurentino. 0 passado desvendado. Revista Veja, São Paulo, 11 nov. 1998. p. 138. 